Revista Brasileira de Odontologia Legal - RBOL

ISSN 2359-3466

http://www.portalabol.com.br/rbol

\title{
Violência doméstica
}

\section{CONHECIMENTO E ATUAÇ̃̃O DE CIRURGIÕES-DENTISTAS E ESTUDANTES DE ODONTOLOGIA FRENTE À VIOLÊNCIA CONTRA A MULHER, COM ÊNFASE NA NOTIFICAÇÃO COMPULSÓRIA.}

\section{Knowledge and practice of professionals and dentistry students about violence against women, with emphasis on compulsory notification.}

\author{
Maria Fernanda Silva da LUZ'1, Denise Bolten Lucion LORETO², Beatriz \\ Álvares Cabral de BARROS ${ }^{3}$. \\ 1. Graduação em Odontologia, Universidade Federal de Santa Catarina, Santa Catarina, Brasil. \\ 2. Especialista em Odontologia Legal, Perita Oficial, Tribunal de Justiça do Rio Grande do Sul, RS, Brasil. \\ 3. Professora Associada do Departamento de Odontologia, Odontologia Legal, Universidade Federal de Santa \\ Catarina, Santa Catarina, Brasil.
}

\begin{tabular}{ll}
\hline Informação sobre o manuscrito & Autor(a) para contato: \\
Recebido em: 05 Fevereiro 2021 & Beatriz Álvares Cabral de Barros. \\
Aceito em: 16 Maio 2021 & R. Delfino Conti, 1240 - Dept de Odontologia/CCS/UFSC \\
& Trindade, Florianópolis - SC, Brasil. CEP: 88036-020. \\
& E-mail: beatriz.barros@gmail.com.
\end{tabular}

\section{RESUMO}

Apesar do aprimoramento no combate à violência contra a mulher, o número de casos aumenta. $O$ cirurgião-dentista, pela proximidade no atendimento clínico e a possibilidade de comprovar as agressões físicas sofridas na face do paciente, exerce um relevante papel na notificação dos casos. O objetivo deste estudo foi analisar os conhecimentos e atitudes de cirurgiões-dentistas e graduandos em Odontologia sobre a notificação obrigatória em casos de violência contra a mulher e definir a necessidade da ênfase neste assunto nos cursos de Odontologia. Foi realizada a pesquisa observacional, transversal, quantitativa através de questionário no Google Forms ${ }^{\circledR}$. Os resultados mostram que $65 \%$ desconheciam notificação compulsória; $67,7 \%$ relataram confortáveis para fazê-la, mas apenas $5,4 \%$ já a fizeram e $99,1 \%$ afirmaram achar necessário que este assunto seja mais discutido nos currículos de graduação. 0 estudo alerta que a maioria não conhece sobre notificação compulsória, sendo importante enfatizar nos currículos de graduação a obrigatoriedade da notificação em casos de violência contra a mulher, e assim, contribuindo para a redução de casos de violência contra a mulher.

PALAVRAS-CHAVE

Odontologia legal; Notificação compulsória; Violência contra a mulher.

\section{INTRODUÇÃO}

A violência contra a mulher sempre esteve presente em nossa sociedade, porém, no Brasil, o primeiro passo contra esse ato só foi dado no ano de 1984, quando o país ratificou a Convenção para a Eliminação de Todas as Formas de Discriminação Contra a
Mulher $^{1}$. No ano de 1985 foi criada a primeira Delegacia Especializada da mulher no Brasil, na cidade de São Paulo; em 1993, a Declaração sobre a Eliminação da Violência contra as mulheres foi adotada pela Assembleia Geral das Nações Unidas (AGNU), com definições importantes sobre 
violência contra a mulher ${ }^{2}$. Em 1996, foi adotada a Convenção Interamericana para Prevenir, Punir e Erradicar a Violência Contra a Mulher, considerando-a uma violação aos direitos humanos e liberdades fundamentais ${ }^{3}$.

Em 2001, após a repercussão do caso de Maria da Penha Maia Fernandes, a Organização dos Estados Americanos (OEA) condenou o Brasil a definir uma legislação para esse tipo de violência e recomendou a erradicação da tolerância estatal nesses casos $^{2}$.

Então, em 2004, foi promulgada a Lei $n^{\circ}$ 10.886/04 ${ }^{4}$ alterando o Art, 129 do Código Penal Brasileiro e acrescentando a violência doméstica como crime. Dois anos depois foi promulgada a Lei $n^{\circ} 11.340 / 06^{5}$, Lei Maria da Penha, que define violência doméstica, familiar e conjugal contra a mulher, estabelece medidas preventivas, possibilita a prisão em flagrante e agrava a pena para os agressores.

De acordo com o Fórum Brasileiro de Segurança Pública ${ }^{6}$ (2020), apesar do amparo legal, o número de assassinatos de mulheres, como o feminicídio, aumentou desde o início da pandemia da Covid-19. David et al. ${ }^{7}$ (2020), também verificaram um aumento dos feminicídios entre 2008 e 2015. Possibilitando uma visão internacional da violência contra a mulher, um estudo realizado por Guisbert ${ }^{8}$ (2019), mostrou que em 2016 e 2017, 215 feminicídios foram registrados na Bolívia. E mundialmente, estima-se que $7 \mathrm{em}$ cada 10 mulheres serão espancadas, estupradas, abusadas ou mutiladas durante sua vida ${ }^{9}$.

Estudo realizado em Rondônia por Oliveira et al. $^{10}$ (2018), abrangendo levantamentos de 2007 a 2015, apresenta o perfil da vítima: mulheres na faixa etária predominante dos 19 aos 39 anos. Independentemente da idade, as mulheres pardas ou negras são mais atingidas, e na escolaridade, as com apenas ensino fundamental se sobressaíram. O estudo de Garbin et al. ${ }^{11}$ (2006) aponta ser a região de cabeça e pescoço a mais atingida nas agressões contra as mulheres. Nessa região corporal, a face é a mais acometida por ser área exposta e pouco protegida ${ }^{11}$. Garcez et al. $^{12}$ (2019), mostram que, na face, a região orbital é a mais atingida, seguida da frontal e labial. As lesões podem ocasionar alterações permanentes anatômicas e funcionais. Assim, profissionais da odontologia têm importante papel na constatação e tratamento de lesões resultantes da violência doméstica ${ }^{13}$.

No Brasil, em 24 de novembro de 2003 foi criada a Lei $10.778 / 03^{14}$, estabelecendo a notificação compulsória de casos de violência contra a mulher. Em 5 de novembro de 2004, a Portaria № $2.406^{15}$ instituiu o serviço de notificação compulsória de violência contra a mulher, e aprovou o instrumento e o fluxo para a notificação. Desde então, a ficha de notificação de violência interpessoal e/ou autoprovocada deve também ser preenchida em casos suspeitos ou confirmados de violência contra a mulher ${ }^{16}$. Não é necessário conhecer o agressor, mas é obrigatório (compulsório) o preenchimento do documento por parte do profissional da saúde $^{17}$. A ficha deve ser preenchida em duas vias, uma permanece no prontuário da paciente e a outra é encaminhada para a vigilância epidemiológica do município ${ }^{18}$.

A notificação compulsória é de origem formal, institucional e sigilosa, logo, não instaura uma denúncia e não expõe profissionais da saúde a reações de 
represálias $^{19}$. Já a denúncia refere-se a uma iniciação de processo penal planejado pelo Ministério Público. Uma não invalida a outra e podem ser realizadas concomitantemente. Portanto, a notificação compulsória de violência contra a mulher não é considerada uma denúncia ${ }^{16}$.

No dia 10 de dezembro de 2019 foi promulgada a Lei $13.931 / 19^{20}$ tornando obrigatório aos serviços de saúde públicos e privados comunicar às autoridades policiais as suspeitas ou confirmações de violência contra a mulher num prazo de até 24 horas, para as providências cabíveis e fins estatísticos. $\mathrm{O}$ ato de comunicar às autoridades não instaura denúncia por parte do profissional da saúde, cabendo à autoridade policial essa ação. Publicada em 18 de janeiro de 2021, a portaria GM/MS № $78^{21}$, estabeleceu diretrizes para comunicação de casos de violência contra a mulher às autoridades policiais. A portaria determina que cabe à unidade de saúde comunicar à autoridade policial no prazo de 24 horas da constatação da violência. Nos casos em que não for possível a comunicação, caberá à autoridade sanitária estadual proceder à comunicação à autoridade policial no prazo de 24 horas após a consolidação semanal da base estadual do Sistema de Informação de Agravos de Notificação do Ministério da Saúde (VIVA SINAN). A comunicação deve ser feita de forma sintética e consolidada, não identificando a vítima e nem o profissional de saúde. Porém, em caráter excepcional, em caso de risco à comunidade ou à vítima e ao juízo da autoridade sanitária, a comunicação deverá ser feita com identificação da vítima, com conhecimento desta ou do seu responsável. A portaria também determina que a ficha de notificação compulsória dos casos de violência do VIVA SINAN, bem como o prontuário médico, não devem, em nenhuma circunstância, ser utilizados como documento de comunicação nos casos de violência às autoridades policiais, sob risco pena de responsabilização administrativa, civil e penal. Além disso, toda a comunicação externa deverá ser feita em meio seguro e devidamente assinado pela autoridade sanitária estadual.

Além da violência contra a mulher, outros eventos de saúde pública a serem notificados estão listados na Portaria n ${ }^{\circ} 264$ de 17 de Fevereiro de $2020^{22}$.

O cirurgião-dentista, pela proximidade no atendimento clínico e a possibilidade de comprovar as agressões físicas sofridas pela paciente, tem relevante papel na notificação da violência e assim, nas políticas de proteção. Conhecer a legislação sobre notificação compulsória de violência contra a mulher e como deve ser feita é parte importante da formação profissional. Este estudo objetivou analisar os conhecimentos e atitudes de cirurgiões-dentistas e graduandos em Odontologia sobre a notificação compulsória em casos de violência contra a mulher e definir a necessidade da ênfase neste assunto nos cursos de Odontologia.

\section{MATERIAIS E MÉTODOS}

É um estudo transversal, observacional, quantitativo, executado pela criação e aplicação de um questionário online, aprovado pelo Comitê de Ética em Pesquisa envolvendo seres humanos da Universidade Federal de Santa Catarina, sob parecer $n^{\circ}$ 3.549.449 (CAAE n. 16613219.7.0000.0121). 
O questionário foi elaborado com a ferramenta Google Forms ${ }^{\circledR}$ (Google Docs ${ }^{\circledR}$ ) baseando-se em estudos anteriores sobre o tema e dúvidas comuns a respeito do assunto. Foi disponibilizado juntamente com Termo de Consentimento Livre e Esclarecido (TCLE), de modo remoto, durante os meses de Setembro, Outubro e Novembro de 2019, via grupos de Odontologia no Facebook, contatos da área Odontológica no Linkedln, grupos de Whatsapp de estudantes de Odontologia e de cirurgiões-dentistas com inscrição em qualquer estado, e na mídia interna do curso de graduação em Odontologia da Universidade Federal de Santa Catarina (UFSC) para os alunos. O link foi disponibilizado nas mídias sociais citadas. Os interessados acessavam o link e, após aceitarem o termo de consentimento, avançavam nas respostas do questionário no formulário Google. Foram coletadas informações do respondente relacionadas a sexo e status na profissão (graduado ou estudante). Para os graduados, informações referentes ao tempo que exercem a profissão (se menos ou mais de 13 anos) e para estudantes, sobre qual fase estão cursando.

A análise estatística utilizou teste Qui-quadrado, com margem de erro de $5 \%$ e intervalo de confiança (IC) de 95\%. Foram incluídos apenas cirurgiões-dentistas e estudantes maiores de 18 anos de faculdades brasileiras.

\section{RESULTADOS}

Foram analisados 223 questionários, sendo 177 (79,42\%) respondidos por mulheres e $46(20,6 \%)$ por homens. Foram 137 questionários respondidos por estudantes de
Odontologia $(61,4 \%)$ e 86 por cirurgiõesdentistas $(38,6 \%)$.

$\mathrm{Na}$ tabela 1, os participantes que relataram saber o que é notificação compulsória, responderam também como tomaram conhecimento. As respostas mais frequentes diziam ter tomado conhecimento buscando informação (47,2\%), na internet, estudando ou lendo sobre o assunto, ou em aula da graduação $(25,64 \%)$.

Foi questionado aos que responderam que não se sentiriam confortáveis para fazer a notificação, o porquê de se sentirem assim. Muitos motivos foram dados por ser uma resposta dissertativa, porém os mais frequentes foram:

- Medo de represália (ao profissional ou à vítima) (33,3\%);

- Não ter conhecimento suficiente sobre o assunto $(20,8 \%)$;

- Medo $(10,4 \%)$.

Dentre os participantes que disseram ter capacidade de identificar os casos de violência, foi questionado o porquê. A maioria acredita conseguir identificar por evidências como lesões na face/boca, corpo e lesões fora de contexto $(50,4 \%)$. Outra parcela $(39,2 \%)$ acredita conseguir identificar observando comportamento da paciente, que pode levar a suspeitas.

Dos participantes que se relataram incapazes de identificar casos de violência, $58,7 \%$ alegam falta de conhecimento do assunto, pouco discutido na graduação. Outros 15,2\% sentem-se incapazes de identificar, pois a vítima poderia mentir ou esconder que foi agredida. 
Tabela 1: Frequência das respostas sobre notificação compulsória em caso de violência doméstica.

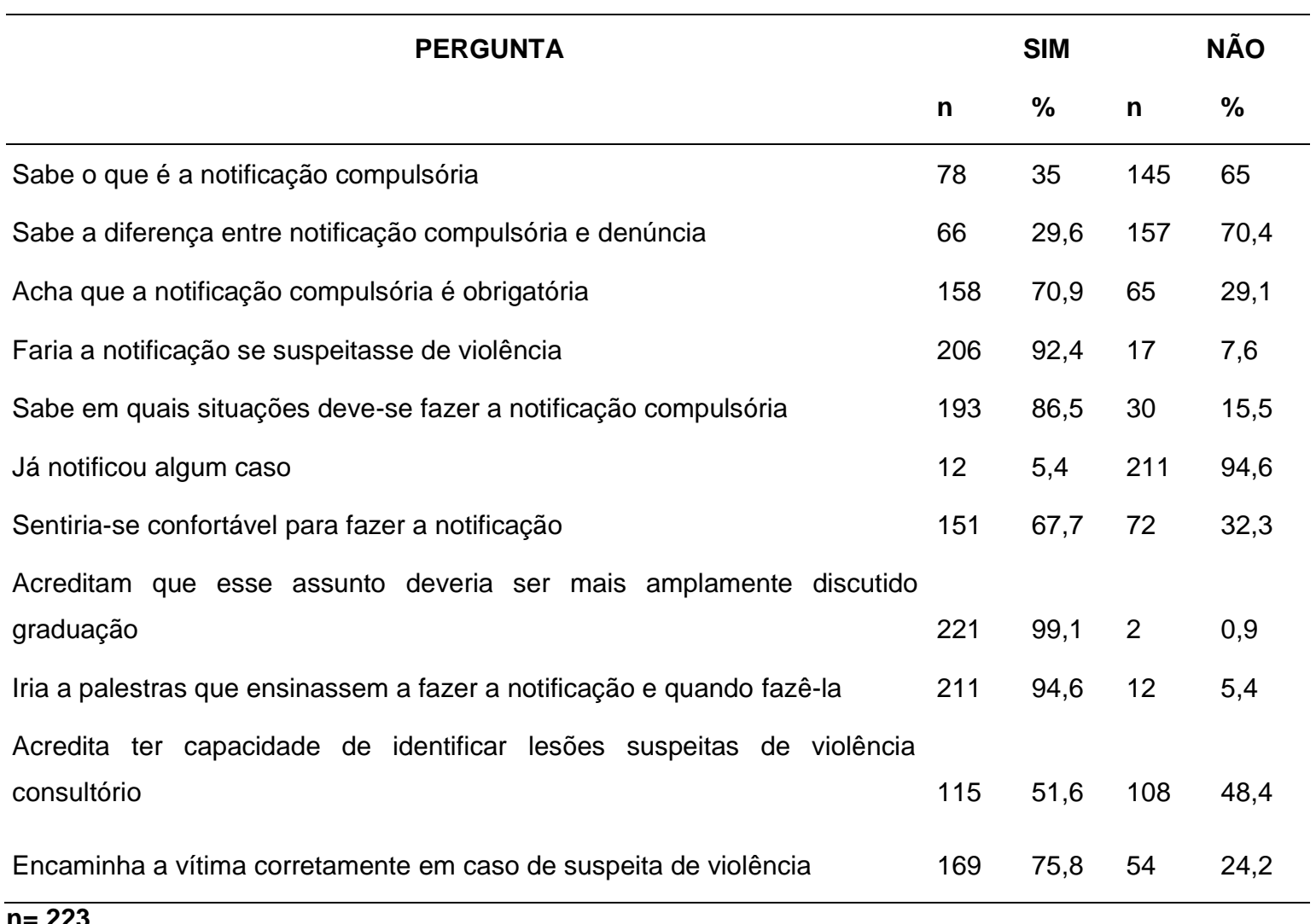

A comparação de respostas dos cirurgiões-dentistas graduados há mais de 13 anos e os graduados há menos de 13 anos não revelou diferença estatisticamente significativa $(p<0,05)$. A comparação entre os alunos da $1^{\circ}$ a $5^{\circ}$ fase e os da $6^{\circ}$ a $10^{\circ}$ fase também não apresentou diferença estatística $(p<0,05)$.

Por último, a comparação das respostas dos cirurgiões dentistas $(n=86)$ e estudantes de Odontologia $(n=137)$, correspondendo ao total da amostra $(n=223)$, apontou diferença estatisticamente significativa $(p<0,05)$ (Tabela 2).

\section{DISCUSSÃO}

Este estudo constatou que $65 \%$ dos participantes não sabem o que é a notificação compulsória. O resultado corrobora com estudo realizado por Fernandes et al. $(2017)^{18}$ que verificou que $74 \%$ dos cirurgiões dentistas relataram não saber notificar e $70 \%$ desconheciam o assunto, e apenas $26 \%$ dos cirurgiões-dentistas notificaram casos de violência por eles diagnosticados.

O presente estudo constatou que 29,6\% sabem a diferença entre notificação compulsória e denúncia, e que apenas cerca de $5 \%$ já realizaram uma notificação compulsória. De acordo com Garbin et al. $(2016)^{23}$ a falta de conhecimento da legislação contribui para a omissão e consequente ineficácia do instrumento legal. É importante sinalizar a necessidade de treinamento dos profissionais em relação ao preenchimento da ficha de notificação, bem como dos conceitos abordados para propiciar uma avaliação adequada dos casos. 
Tabela 2 - Frequência das respostas dos cirurgiões-dentistas e dos estudantes de odontologia.

\begin{tabular}{|c|c|c|c|c|}
\hline \multirow[t]{2}{*}{ PERGUNTA } & \multicolumn{2}{|c|}{$\begin{array}{l}\text { Cirurgiões- } \\
\text { dentistas } \\
(n=86)\end{array}$} & \multicolumn{2}{|c|}{$\begin{array}{l}\text { Estudantes } \\
(\mathrm{n}=137)\end{array}$} \\
\hline & $\mathbf{n}$ & $\%$ & $\mathbf{n}$ & $\%$ \\
\hline Sabe o que é notificação compulsória & 51 & 59,3 & 27 & 19,2 \\
\hline Sabe a diferença entre notificação compulsória e denúncia & 48 & 55,8 & 18 & 13,1 \\
\hline Acha que a notificação compulsória é obrigatória & 67 & 77,9 & 91 & 66,4 \\
\hline Faria a notificação se suspeitasse de violência & 76 & 88,4 & 130 & 94,9 \\
\hline Sabe em quais situações deve-se fazer a notificação compulsória & 74 & 86 & 119 & 86,9 \\
\hline Já notificou algum caso & 10 & 11,6 & 2 & 1,4 \\
\hline Sentiria-se confortável para fazer a notificação & 56 & 65,1 & 95 & 69,3 \\
\hline $\begin{array}{l}\text { Acreditam que esse assunto deveria ser mais amplamente discutido na } \\
\text { graduação }\end{array}$ & 86 & 100 & 135 & 98,5 \\
\hline Iria a palestras que ensinassem a fazer a notificação e quando fazê-la & 81 & 94,2 & 130 & 94,9 \\
\hline $\begin{array}{l}\text { Acredita ter capacidade de identificar lesões suspeitas de vio } \\
\text { consultório }\end{array}$ & 51 & 59,3 & 64 & 46,7 \\
\hline Encaminha a vítima corretamente em caso de suspeita de violência & 57 & 66,3 & 112 & 81,7 \\
\hline
\end{tabular}

Outra medida importante seria os gestores criarem estratégias para revisar os dados, identificar inconsistências e corrigir antes de encaminhar para o nível estadual. O envio de informações inadequadas pode influenciar as políticas de saúde e dificultar 0 enfrentamento das violências na sociedade ${ }^{24}$. Além disso, é necessário que as instituições de ensino deem maior ênfase à prevenção e combate à violência. $\mathrm{O}$ mesmo artigo alega que a legislação brasileira não dispõe de uma boa orientação aos profissionais e ressalta a necessidade de treinamento e articulação entre profissionais da saúde, da educação, advogados, entre outros, para um trabalho interdisciplinar na prevenção e combate da violência.

O trabalho de Garbin et al. $(2015)^{25}$ aponta que as principais causas de subnotificação vão desde a falta de capacitação de profissionais a ameaças que sofrem dos autores de violência. Essa informação confirma as respostas obtidas neste estudo, pois $20,8 \%$ não se sentem capacitados para notificar, 99\% acreditam que esse assunto deveria ser mais discutido na graduação e 33,3\% relataram sentir medo de represália por notificar.

Uma pesquisa realizada em São Paulo entre 2013 e 2014, relatou que $60 \%$ dos cirurgiões dentistas afirmaram que frente a uma situação de violência, se sentiriam no dever de tomar alguma atitude. Dentre os que se propuseram a tomar alguma atitude, apenas $36,4 \%$ notificariam o caso aos órgãos responsáveis; $31,8 \%$ orientariam a vítima a procurar ajuda e $18,2 \%$ buscariam mais informações sobre as providências cabíveis e legais possíveis ${ }^{23}$. De acordo com o presente estudo, $75,8 \%$ dos participantes orientariam a 
vítima a registrar um boletim de ocorrência na delegacia, fariam a notificação compulsória da violência e a encaminhariam para o órgão competente; $13 \%$ responderam que apenas orientariam a vítima a ir à delegacia registrar um boletim de ocorrência; $6,3 \%$ apenas tratariam as lesões e $4,9 \%$ fariam a notificação compulsória de violência contra a mulher e guardariam cópia no prontuário do paciente.

No presente estudo, $48,4 \%$ acreditam não ter capacidade de identificar casos de violência contra a mulher em seu consultório, sendo que $58,7 \%$ relatam falta de conhecimento sobre 0 assunto, pouco discutido na graduação. $O$ artigo de Garbin et al. $(2015)^{25}$ traz como causas o despreparo, desinteresse, falta de tempo para escutar o paciente nos atendimentos e o fato de ater-se somente às lesões físicas. Os autores salientam a falta de abordagem do tema na graduação, o desconhecimento da legislação e da obrigação de notificar. Assim, os egressos não se sentem preparados para oferecer atenção efetiva às vítimas, possibilitando que as lesões e suas causas passem despercebidas.

Segundo Ayres (2013) ${ }^{26}$, apesar dos avanços no ensino da graduação e da pósgraduação, ainda existem lacunas na transmissão deste conhecimento. Ressalta a necessidade de investimento na qualificação de docentes e discentes, para que futuros cirurgiões-dentistas sejam capazes de identificar casos de maus-tratos e zelar pela saúde e dignidade da paciente.

Percebe-se como é precária a notificação de violência atualmente, o que evidencia também a importância de entender o perfil da vítima e estar atento aos sinais que ela pode apresentar durante $o$ atendimento.
Só assim, será possível avaliar se a notificação compulsória de violência contra a mulher é a alternativa correta a se seguir e evitar que mais casos sejam subnotificados.

No presente estudo, $78,9 \%$ acreditam ser a face a região mais acometida em casos de agressão contra a mulher. Segundo Castro $(2011)^{27}, 58 \%$ das vítimas de violência contra mulher apresentam lesões faciais e buco-dentais. As lesões craniofaciais mais encontradas foram equimose $e$ escoriação, e as regiões mais atingidas foram a orbitária e cervical. No complexo dentoalveolar há prevalência de fraturas dentárias, principalmente dos incisivos superiores. Marques et al. (2016) ${ }^{13}$ acrescentam que, além das equimoses e escoriações, o edema é o terceiro tipo de sinal mais visto em mulheres vítimas de agressão. Concordam também que a região orbitária é a mais prevalente, mas discorda ao dizer que a labial é a segunda mais prevalente, seguida da frontal.

$$
\text { Segundo Castro (2011) }{ }^{27} \text {, o }
$$

cirurgião-dentista é habilitado para realizar as perícias de lesões bucais e faciais e sua presença nos serviços periciais é importante, especialmente para avaliar os danos provocados, às consequências geradas e os nexos causal e temporal dos casos. Quando no exercício da clínica odontológica deve estar atento às recomendações éticas e legais como a notificação compulsória, o sigilo profissional e a adequada descrição das lesões.

Além de instrumento de política pública, a notificação é estratégia primordial do Ministério da Saúde nas ações contra a violência, contribui no seu dimensionamento e assegura a implementação de políticas públicas de vigilância e assistência às vítimas. $A$ atuação preventiva no combate à violência é 
relevante, pois reduz ocorrências, evita a perda da qualidade de vida e os gastos elevados nos serviços de atendimento ${ }^{25}$.

\section{CONCLUSÃO}

O presente estudo mostra que a maioria dos estudantes e graduados não conhece adequadamente a notificação compulsória e a legislação a ela relacionada. Apenas uma pequena parte tomou conhecimento pesquisando sobre o assunto e a minoria através de aulas na graduação. Apesar disso, uma parcela significativa sabe que a notificação é obrigatória e faria a notificação mesmo em casos de suspeita.

Frente a casos de violência contra a mulher, ou mesmo diante da suspeita, a maior parte dos entrevistados (estudantes e graduados), quando dadas as opções, acertaram ao indicar quando fazer a notificação e o correto encaminhamento da ficha de notificação compulsória aos órgãos competentes.

Por fim, o estudo aponta que a maioria dos participantes relata não receber adequada informação sobre notificação compulsória durante sua formação acadêmica. Conclui-se assim, ser de suma importância enfatizar nos currículos de graduação a relevância da notificação compulsória em casos de violência contra a mulher, possibilitando que contribuam para a redução de casos de violência contra a mulher.

\begin{abstract}
Despite the improvement in the fight against violence against women, the number of cases increases. The dentist, due to the proximity to clinical care and the possibility of proving the physical aggressions suffered on the patient's face, plays a relevant role in the notification of cases. The aim of this study was to analyze the knowledge and attitudes of dentists and dentistry undergraduates about compulsory notification in cases of violence against women and to define the need for emphasis on this subject in dentistry courses. Observational, transversal and quantitative research was carried out through a questionnaire created in Google Forms ${ }^{\circledR}$. The results show that $65 \%$ didn't know about compulsory notification; $67.7 \%$ reported being comfortable to do it, but only $5.4 \%$ have already done it and $99.1 \%$ said they think it necessary for this subject to be further discussed in undergraduate curricula. The study demonstrated that most do not know about compulsory notification, it is important to emphasize in the undergraduate curricula the relevance of compulsory notification in cases of violence against women, and thus contribute to the reduction of cases of violence against women.
\end{abstract}

\title{
KEYWORDS
}

Forensic Dentistry; Compulsory notification; Violence against women.

\section{REFERÊNCIAS}

1. Brasil. Decreto no 89.460 , de 20 de março de 1984. Promulga a Convenção sobre a Eliminação de Todas as Formas de Discriminação contra a Mulher, 1979. Disponível em: https://www2.camara.leg.br/legin/fed/decret 1980-1987/decreto-89460-20-marco-1984439601-publicacaooriginal-1-pe.html Acesso em: 25 jun. 2020.

2. Daruge E, Daruge Júnior E, Francesquini Júnior L. Tratado de Odontologia Legal e Deontologia. Rio de Janeiro: Santos, 2016.

3. Brasil. Decreto $n^{0} 1.973$, de 1 de agosto de 1996. Promulga a Convenção Interamericana para Prevenir, Punir e Erradicar a Violência contra a Mulher, concluída em Belém do Pará, em 9 de junho de 1994. Disponível em: http://www.planalto.gov.br/ccivil 03/decreto 1996/D1973.htm Acesso em: 25 jun. 2020.

4. Brasil. Lei $\mathrm{n}^{-} \mathbf{1 0}$ 1086, de 17 de junho de 2004. Acrescenta parágrafos ao art. 129 do Decreto-Lei no 2.848 , de 7 de dezembro de 1940 - Código Penal, criando o tipo especial denominado "Violência Doméstica". Disponível em: http://www.planalto.gov.br/ccivil 03/ Ato20 04-2006/2004/Lei/L10.886.htm Acesso em: 25 jun. 2020.

5. Brasil. Lei $\mathrm{n}^{0} 11.340$, de 7 de agosto de 2006. Cria mecanismos para coibir a violência doméstica e familiar contra a 
mulher, nos termos do $\S 8^{\circ}$ do art. 226 da Constituição Federal, da Convenção sobre a Eliminação de Todas as Formas de Discriminação contra as Mulheres e da Convenção Interamericana para Prevenir, Punir e Erradicar a Violência contra a Mulher; dispõe sobre a criação dos Juizados de Violência Doméstica e Familiar contra a Mulher; altera o Código de Processo Penal, o Código Penal e a Lei de Execução Penal; e dá outras providências. Disponível em: http://www.planalto.gov.br/ccivil 03/ Ato20 04-2006/2006/Lei/L11340.htm Acesso em: 25 jun. 2020.

6. Fórum Brasileiro de Segurança Pública. Violência doméstica durante a pandemia de Covid-19. Abril, 2020 Abril. 17 p. Disponível em:

https://forumseguranca.org.br/wpcontent/uploads/2018/05/violenciadomestica-covid-19-v3.pdf Acesso em: 4 de Abril de 2020.

7. Vaz DLM, Minamisava R, Oliveira VPV et al. Perfil dos óbitos femininos por homicídios no município de Goiânia. Rev. Bras. Enferm. 2020; 73 (Suppl 4): e20180985. https://doi.org/10.1590/00347167-2018-0985.

8. Richard CGJ. Factores frecuentes del feminicidio en Bolivia. Rev. Méd. La Paz [Internet]. 2019 [citado 2021 Mar 28] ; 25( 2 ): 42-46. Disponível em: http://www.scielo.org.bo/scielo.php?script= sci arttext\&pid=S172689582019000200006\&lng=es.

9. ONU. No Dia Internacional da Mulher, ONU pede fim de todos os tipos de violência de gênero. 8 mar. 2013. Disponível em:

https://nacoesunidas.org/no-diainternacional-da-mulher-onu-pede-fim-detodos-os-tipos-de-violencia-degenero/ Acesso em: 22 maio 2019.

10. Oliveira CAB, Alencar LN, Cardena RR, Moreira KFA, Pereira PPS, Fernandes DER. Perfil da vítima e características da violência contra a mulher no estado de Rondônia - Brasil. Rev Cuid . 2019 Apr; 10(1): e573. https://doi.org/10.15649/cuidarte.v10i1.573

11. Garbin CAS, Garbin AJI, Dossi AP, Dossi MO. Violência doméstica: análise das lesões em mulheres. Cad. Saúde Pública [Internet]. 2006 Dec; 22(12): 2567-2573. https://doi.org/10.1590/S0102311X2006001200007.

12. Garcez RHM, Thomaz EBAF, Marques RC, Azevedo JAP, Lopes FF. Caracterização de lesões bucomaxilofaciais decorrentes de agressão física: diferenças entre gênero. Ciênc. saúde coletiva [Internet]. 2019 Mar; 24(3):
1143-52. https://doi.org/10.1590/141381232018243.33892016.

13. Marques RC et al. Danos bucomaxilofaciais em mulheres: registros do instituto médico legal de São Luís, Maranhão - 2010 a 2013. Revista de Pesquisa em Saúde, [S. I.], 2016.

14. Brasil. Lei no 10.778 , de 24 de novembro de 2003. Estabelece a notificação compulsória, no território nacional, do caso de violência contra a mulher que for atendida em serviços de saúde públicos ou privados. Disponível em: http://www.planalto.gov.br/ccivil 03/LEIS/2 003/L10.778.htm Acesso em: 25 jun. 2020.

15. Brasil. Gabinete do Ministro - Ministério da Saúde. Institui serviço de notificação compulsória de violência contra a mulher, e aprova instrumento e fluxo para notificação. Portaria $\mathrm{n}^{\circ} 2.406$, de 5 de Novembro de 2004. Disponível em: http://bvsms.saude.gov.br/bvs/saudelegis/g m/2004/prt24 Acesso em: 3 de Abril de 2020.

16. Brasil. Ministério da Saúde. Orientações para notificação e atendimento: A notificação compulsória de violências e a comunicação a outras autoridades. Orientações para notificação e atendimento, [s. I.], 16 maio 2018. Disponível:

https://www.saude.gov.br/vigilancia-emsaude/vigilancia-de-violencias-e-acidentesviva/vigilancia-de-violencias/orientacoespara-notificacao-e-atendimento Acesso em: 25 jun. 2020.

17. Santinon EP, Gualda DMR, da Silva LCFP. Violência contra a mulher: notificação compulsória e outros instrumentos legais de uso dos profissionais de saúde. In: Âmbito Jurídico, Rio Grande, XIII, n. 74, mar 2010. Disponível em: https://ambitojuridico.com.br/cadernos/direi to-administrativo/violencia-contra-a-mulhernotificacao-compulsoria-e-outrosinstrumentos-legais-de-uso-dosprofissionais-de-saude Acesso em 5 de maio 2019.

18. Fernandes TB et al. Notificação de violência: conhecimento de cirurgiõesdentistas que atuam na região carbonífera, SC. Revista da ABENO, 2017. Disponível em:

https://revabeno.emnuvens.com.br/revabe no/article/view/482/411 Acesso em: 26 maio 2019.

19. Conceição JC, Gusmão MEN, Souza SS, Gomes NP. Elementos que dificultam a notificação da violência: percepção dos profissionais de saúde. Revista Baiana de Enfermagem, Salvador, ano 2012, v. 26, n. 2 , p. 468-477, 22 mar. 2012. http://dx.doi.org/10.18471/rbe.v26i2.6287. 
20. Brasil. Lei $n^{\circ} 13.931$, de 10 de dezembro de 2019. Altera a Lei no 10.778 , de 24 de novembro de 2003, para dispor sobre a notificação compulsória dos casos de suspeita de violência contra a mulher. Disponível em: http://www.planalto.gov.br/ccivil 03/ ato20 19-2022/2019/lei/L13931.htm Acesso em: 25 jun. 2020.

21. Brasil. Gabinete do Ministro - Ministério da Saúde. Altera a Portaria de Consolidação GM/MS no 4, de 28 de setembro de 2017 , para dispor sobre as diretrizes para a comunicação externa dos casos de violência contra a mulher às autoridades policiais, no âmbito da Lei no 10.778 , de 24 de novembro de 2003. Portaria GM/MS no 78, de 18 de Janeiro de 2021. Disponível em:

http://bvsms.saude.gov.br/bvs/saudelegis/g m/2021/prt0078 1901 2021.html Acesso em: 3 de Abril de 2020.

22. Brasil. Gabinete do Ministro - Ministério da Saúde. Altera a Portaria de Consolidação nํ 4/GM/MS, de 28 de setembro de 2017, para incluir a doença de Chagas crônica, na Lista Nacional de Notificação Compulsória de doenças, agravos e eventos de saúde pública nos serviços de saúde públicos e privados em todo 0 território nacional. Portaria no 264, de 17 de Fevereiro de 2020. Disponível em: http://portalsinan.saude.gov.br/images/doc umentos/Legislacoes/Portaria N 26417 FEVEREIRO 2020.pdf Acesso em: 3 de Abril de 2020.

23. Garbin CAS et al. Percepção e atitude do cirurgião-dentista servidor público frente à violência intrafamiliar em 24 municípios do interior do estado São Paulo, 2013-2014. Epidemiol. Serv. Saúde, Brasília, v. 25, n. 1, p. 179-186, Mar. 2016. https://doi.org/10.5123/s167949742016000100019.

24. Girianelli VR et al. Qualidade das notificações de violências interpessoal e autoprovocada no Estado do Rio de Janeiro, Brasil, 2009-2016. Cad. Saúde Coletiva, Rio de Janeiro, 2018. https://doi.org/10.1590/1414462X201800030075.

25. Garbin CAS, Dias IA, Rovida TS, Garbin AJI. Desafıos do profissional de saúde na notifıcação da violência: obrigatoriedade, efetivação e encaminhamento. Ciênc. saúde coletiva [Internet]. 2015 June ; 20(6): 1879-90. http://dx.doi.org/10.1590/141381232015206.13442014

26. Ayres KCM - Violência doméstica, perfil da vítima e o papel do dentista: Uma revisão crítica da literatura, Monografia. Piracicaba, São Paulo. 2013. Disponível em: http://www.bibliotecadigital.unicamp.br/doc ument/?down=000903196 Acesso em 21 jan. 2021.

27. Castro TL. Lesões Craniofaciais em mulheres vítimas de violência doméstica e familiar: registros do Departamento Médico Legal em Vitória (ES) entre 2004 e 2008, Monografia. Faculdade de Odontologia de Piracicaba, Universidade Estadual de Campinas, Piracicaba, São Paulo, 2011, 117 p. Disponível em: http://repositorio.unicamp.br/jspui/handle/R EPOSIP/290756. Acesso em: 30 jan. 2020. 